\title{
SKALA EVALUASI LINGKUNGAN BELAJAR KLINIK, SUPERVISI DAN DOSEN PERAWAT (CLINICAL LEARNING ENVIRONMENT, SUPERVISION AND NURSE TEACHER - CLES+T) VERSI BAHASA INDONESIA: VALIDITAS DAN RELIABILITAS
}

\author{
Ratna Puji Priyanti ${ }^{*}$, Pepin Nahariani \\ Sekolah Tinggi Ilmu Kesehatan Pemkab Jombang, J1. Dr. Sutomo No.75-77 \\ Email: ns.ratnapuji@gmail.com
}

\begin{abstract}
The practice of clinical learning is a bridge for gap between theory and practice. By learning practice clinics, nursing students are encouraged to prepare for graduate and worked in clinical practice. Evaluation of clinical learning environment needed to be able to create a conducive learning environment. CLES+T scale has been validated and used in more than 30 countries. The research aims is to validate the CLES+T scale into Indonesian version. CLES $+\mathrm{T}$ has been translated into Indonesian version using the rules of the international translation backward and forward. Construct validity using 4 oang experts in nursing and education. The SCVI result was 0.9405. Validity analysis was tested using PCA (Principal Component Analysis) with $\mathrm{N}=46$. Reliability tested using Cronbach's alpha. The results obtained eigenvalue and explanation precentage of $67 \%$, it is concluded that the eigenvalue factors of CLES+T were sufficient. Cronbach alpha was obtained for 0786. CLES+T Indonesian version has been validated and can be used to evaluate learning environment as perceived by nursing students in Indonesia.
\end{abstract}

Keywords: Education, Nursing, Clinical Learning, Students

\begin{abstract}
Abstrak : Praktik pembelajaran klinik merupakan jembatan penghubung kesenjangan antara teori dan praktik. Dengan praktik pembelajaran klinik, mahasiswa keperawatan didorong untuk mempersiapkan diri sebelum diluluskan dan bekerja di praktik klinik. Evaluasi mengenai lingkungan pembelajaran klinik diperlukan untuk menciptakan lingkungan pembelajaran yang kondusif. Skala CLES+T telah tervalidasi dan digunakan di lebih dari 30 negara. Tujuan penelitian ini untuk memvalidasi instrumen CLES+T dalam versi bahasa Indonesia. CLES+T telah diterjemahkan ke dalam Bahasa Indonesia menggunakan aturan terjemahan internasional secara backward dan forward. Construct validity menggunakan 4 orang ahli di bidang keperawatan dan pendidikan. Hasil S-CVI $=0.9405$. Analisis validitas diuji menggunakan PCA (Principal Component Analysis) dengan N=46. Reliabiliti diuji menggunakan Cronbach alpha. Hasil eigenvalue dan explanation precentage diperoleh 67\%, hal ini disimpulkan bahwa eigenvalue faktor-faktor dala CLES+T tercukupi. Cronbach alpha diperoleh sebesar 0.786. CLES+T versi Bahasa Indonesia telah tervalidasi dan dapat digunakan untuk mengevaluasi lingkungan pembelajaran menurut persepsi mahasiswa keperawatan di Indonesia.
\end{abstract}

Kata Kunci: Pendidikan, Keperawatan, Pembelajaran Klinik, Mahasiswa 


\section{PENDAHULUAN}

Karakteristik dari pendidikan keperawatan adalah hubungan yang sangat erat antara teori dengan prakik. Hal ini dapat diartikan bahwa salah satu aspek dalam pendidikan keperawatan, baik teori saja ataupun praktik saja tidak dapat berdiri dan dipelajari sendiri (Papastavrou et al., 2010). Dalam pendidikan keperawatan fokus utama adalah pembentukan kemandirian dan pengarahan diri, kedua hal ini sangat penting terutama dalam era globalisasi saat ini. Oleh karena itu, teori dalam pendidikan keperawatan harus ditunjang dengan praktik pembelajaran klinik.

Mahasiswa

keperawatan, dibekali setengah dari proses pendidikan keperawatan (Warne et al., 2010). Praktik pembelajaran klinik juga merupakan jembatan penghubung kesenjangan antara teori dan praktik. Dengan prakttik pembelajaran klinik, mahasiswa keperawatan didorong untuk mempersiapkan diri sebelum diluluskan dan bekerja di praktik klinik. Hal-hal yang tidak didapatkan oleh mahasiswa keperawatan di lingkungan pembelajaran akademik, akan didapatkan pada saaat praktik pembelajaran klinik. Bagaimanapun juga, praktik pembelajaran klinik didefinisikan dengan berbagai cara yang terdiri dari berbagai elemen penting dalam konteks sosial yang kompleks di lingkungan klinik (Papastavrou et al., 2010, Papp et al., 2003, Ip and Kit Chan, 2005, Saarikoski, 2002, Saarikoski et al., 2002).

Pada proses pembelajaran klinik, peran manajer ruangan dalam hal ini adalah kepala ruangan atau clinical instructor atau supervisor sangat diperlukan. Peranan dan metode kepemimpinan oleh manajer ruangan terhadap situasi ruangan yang memungkinkan untuk terciptanya proses pembelajaran bagi mahasiwa. Tidak hanya itu, budaya, dan struktur organisasi juga dilaporkan memiliki peranan penting yang mempengaruhi proses pembelajaran praktik klinik (Saarikoski, 2002). Namun, tak jarang peranan dan fungsi pengajar akademik yang sering berbeda pendapat dengan pengajar klinik memberikan hambatan dan tantangan tersendiri bagi mahasiswa dalam mengikuti proses pembelajaran klinik.

Selama pembelajaran klinik mahasiswa keperawatan menjadi rentan, karena mahasiswa keperawatan pada masa ini dituntut untuk belajar memberikan tindakan keperawatan secara langsung kepada pasien, sekaligus merasa peduli akan reaksi yang diberikan oleh staff keperawatan kepada usaha yang telah mereka lakukan (Chan, 2003). Selama proses pembelajaran praktik klinik mahasiswa diharapkan dapat menumbuhkan kompetensi klinik yang terintegrasi antara ilmu pengetahuan, keahlian dan tingkah laku sebagai perawat. Namun, adanya harapan berlebih staff perawat kepada mahasiswa keperawatan yang dianggap memiliki ilmu pengetahuan yang lebih baru sebagai generasi baru calon tenaga perawat, merupakan tekanan tersendiri bagi mahasiswa keperawatan.

\section{METODE \\ KUESIONER CLES+T}

Kuesioner CLES+T dibuat oleh Saarikoski dan Leino-Kili pada tahun 2008 (Saarikoski et al., 2008) berdasarkan teori mendasar pembelajaran klinik. Instrumen ini terdiri dari 34 pernyataan yang terbagi dalam 5 sub dimensi, yaitu: suasana strategi pembelajaran (pedagogi) di bangsal (9 pernyataan), hubungan supervisi (8 pernyataan), gaya 
kepemimpinan kepala ruangan /manajer bangsal (4 pernyataan), tempat pelayanan keperawatan (4 pernyataan), dan peran dosen perawat (9 pernyataan). Kemudian 1 sub dimensi mengenai kepuasan mahasiswa terhadap penempatan praktek klinik

Instrumen ini menggunakan 5poin skala likert (1-sangat tidak setuju, 2-tidak setuju, 3-netral, 4-setuju,5sangat setuju). Instrumen ini telah digunakan di Finlandia, Swedia, Belgia, Inggris, Irlandia, Blanda, Cyprus, Italia dan Spanyol. Dan, telah tercatat di terjemahkan ke lebih dari 30 bahasa di seluruh dunia. Reliability untuk instrumen ini telah dilaporkan dengan menggunakan Cronbach's alpha dengan nilai berkisar antara .96 (tinggi) ke .77 (marginal) dengan $\mathrm{N}=$ 549 (Saarikoski, 2002).

\section{Proses Terjemah, Uji Validitas dan Reliabilitas Versi Bahasa Indonesia Instrumen CLES+T}

Versi Bahasa Inggris dari CLES+T telah diterjemahkan kedalam Bahasa Indonesia backward-forward dengan menggunakan panduan internasional (Guillemin et al., 1993). Versi Bahasa Indonesia dari CLES+T diterjemahkan oleh 2 penerjemah tersumpah yang bekerja secara mandiri dan terpisah. Kemudian, 2 versi terjemahan Bahasa Indonesia dinilai oleh 2 orang bilingual di bidang keperawatan untuk membuat versi akhir Bahasa Indonesia. Selanjutnya, versi akhir Bahasa Indonesia diterjemahkan oleh 2 penerjemah tersumpah yang terpisah untuk diterjemahkan ulang dari Bahasa Indonesia ke Bahasa Inggris. Setelah itu, versi Bahasa Inggris yang baru dibandingkan dengan versi Bahasa Inggris asli oleh peneliti, untuk menilai konsistensi bahasa dari versi Bahasa Inggris. Content Validity Index (CVI) digunakan untuk menilai validitas isi dari instrument CLES+T versi Bahasa Indonesia (Polit and Beck, 2006). 4 orang ahli diminta unuk menilai CLES+T dalam versi Bahasa Indonesia yang masing-masing memiliki keahlian dibidang pendidikan (2 orang), pelayanan (2 orang). Dari uji CVI didapatkan S-CVI: 0.9405.

Selain itu, uji validitas menggunakan PCA (principal component analysis) juga digunakan untuk menguji korelasi antar item instrumen. Hasil analisis dari ke-5 faktor subdimensi ditemukan total presentasi sebesar $67 \%$. Hal ini menyerupai analisis instrumen CLES+T versi bahasa Inggris (Saarikoski et al., 2008). (Tabel 1)

Reliabilitas instrumen diuji menggunakan koefisien Cronbach's alpha. Dengan nilai alpha $=0.786$. Korelasi inter-item pada masingmasing sub-dimensi berkisar antara 0.915 (tinggi) hingga 0,7 (moderat). Nilai ini hampir menyerupai hasil uji reliabilitas CLES+T versi bahasa Inggris (Saarikoski et al., 2008).

\section{HASIL \& PEMBAHASAN}

a. Hasil

Tabel 1: Analisis faktor CLES+T $(\mathrm{N}=46)$

\begin{tabular}{lccccc}
\hline \multicolumn{1}{c}{ Item Pernyataan } & $\begin{array}{c}\text { Lngkungan } \\
\text { Pembelajaran } \\
\text { (Faktor 1) }\end{array}$ & $\begin{array}{c}\text { Gaya } \\
\text { Kepemimpinan } \\
\text { (Faktor 2) }\end{array}$ & $\begin{array}{c}\text { Perawatan } \\
\text { di } \\
\text { Ruangan } \\
\text { (Faktor 3) }\end{array}$ & $\begin{array}{c}\text { Hubungan } \\
\text { Supervisi } \\
\text { (Faktor 4) }\end{array}$ & $\begin{array}{c}\text { Peran } \\
\text { Posen } \\
\text { (Faktor }\end{array}$ \\
\hline Para staf mudah didekati & 0.347 & & & 5) \\
Saya merasa senang pergi ke bangsal & 0.603 & & & \\
\hline
\end{tabular}




\begin{tabular}{|c|c|c|c|c|c|}
\hline Item Pernyataan & $\begin{array}{l}\text { Lngkungan } \\
\text { Pembelajaran } \\
\text { (Faktor 1) }\end{array}$ & $\begin{array}{l}\text { Gaya } \\
\text { Kepemimpinan } \\
\text { (Faktor 2) }\end{array}$ & $\begin{array}{l}\text { Perawatan } \\
\quad \text { di } \\
\text { Ruangan } \\
\text { (Faktor 3) }\end{array}$ & $\begin{array}{l}\text { Hubungan } \\
\text { Supervisi } \\
\text { (Faktor 4) }\end{array}$ & $\begin{array}{l}\text { Peran } \\
\text { Dosen } \\
\text { Perawat } \\
\text { (Faktor } \\
5 \text { ) }\end{array}$ \\
\hline \multicolumn{6}{|l|}{ saat memulai shift saya } \\
\hline $\begin{array}{l}\text { Selama pertemuan staf (yaitu sebelum } \\
\text { piket) saya merasa nyaman mengambil } \\
\text { bagian dalam diskusi }\end{array}$ & 0.426 & & & & \\
\hline Ada suasana yang positif di bangsal & 0.566 & & & & \\
\hline $\begin{array}{l}\text { Para staf umumnya tertarik dalam } \\
\text { supervisi siswa }\end{array}$ & 0.590 & & & & \\
\hline $\begin{array}{l}\text { Para staf belajar untuk mengenali nama } \\
\text { masing-masing siswa }\end{array}$ & 0.582 & & & & \\
\hline $\begin{array}{l}\text { Ada situasi belajar yang cukup } \\
\text { bermakna di bangsal }\end{array}$ & 0.520 & & & & \\
\hline $\begin{array}{l}\text { Situasi belajar bersifat multi-dimensi } \\
\text { dalam hal isi }\end{array}$ & 0.529 & & & & \\
\hline $\begin{array}{l}\text { Bangsal dapat dianggap sebagai } \\
\text { lingkungan belajar yang baik }\end{array}$ & 0.735 & & & & \\
\hline $\begin{array}{l}\text { MB menganggap staf di bangsalnya } \\
\text { sebagai sumber daya utama }\end{array}$ & & 0.845 & & & \\
\hline MB adalah anggota tim & & 0.809 & & & \\
\hline $\begin{array}{l}\text { Masukan dari MB dapat dengan mudah } \\
\text { dipertimbangkan sebagai situasi } \\
\text { belajar }\end{array}$ & & 0.729 & & & \\
\hline $\begin{array}{l}\text { Upaya masing-masing karyawan } \\
\text { dihargai }\end{array}$ & & 0.769 & & & \\
\hline $\begin{array}{l}\text { Filosofi keperawatan bangsal } \\
\text { ditetapkan dengan jelas }\end{array}$ & & & 0.593 & & \\
\hline $\begin{array}{l}\text { Pasien menerima pelayanan perawatan } \\
\text { individu }\end{array}$ & & & 0.871 & & \\
\hline $\begin{array}{l}\text { Tidak ada masalah dalam arus } \\
\text { informasi terkait dengan pelayanan }\end{array}$ & & & 0.687 & & \\
\hline $\begin{array}{l}\text { Dokumentasi keperawatan jelas } \\
\text { (misalnya rencana keperawatan, catatan } \\
\text { harian prosedur keperawatan dan } \\
\text { sebagainya) }\end{array}$ & & & 0.889 & & \\
\hline $\begin{array}{l}\text { Supervisor saya menunjukkan sikap } \\
\text { positif terhadap supervisi }\end{array}$ & & & & 0.708 & \\
\hline $\begin{array}{l}\text { Saya merasa bahwa saya menerima } \\
\text { supervisi individu }\end{array}$ & & & & 0.523 & \\
\hline $\begin{array}{l}\text { Saya terus menerima masukan dari } \\
\text { supervisor saya }\end{array}$ & & & & 0.727 & \\
\hline $\begin{array}{l}\text { Secara keseluruhan saya puas dengan } \\
\text { supervisi yang saya terima }\end{array}$ & & & & 0.899 & \\
\hline $\begin{array}{l}\text { Supervisi didasarkan pada hubungan } \\
\text { kesetaraan dan mendukung } \\
\text { pembelajaran saya }\end{array}$ & & & & 0.735 & \\
\hline $\begin{array}{l}\text { Ada interaksi timbal balik dalam } \\
\text { hubungan supervisi }\end{array}$ & & & & 0.737 & \\
\hline $\begin{array}{l}\text { Saling menghormati dan persetujuan } \\
\text { lebih disukai dalam hubungan supervisi }\end{array}$ & & & & 0.823 & \\
\hline $\begin{array}{l}\text { Hubungan supervisi ditandai dengan } \\
\text { rasa percaya }\end{array}$ & & & & 0.822 & \\
\hline $\begin{array}{l}\text { Dosen perawat yang memungkinkan } \\
\text { integrasi antara teori dan praktik: }\end{array}$ & & & & & 0.744 \\
\hline $\begin{array}{l}\text { Menurut pendapat saya, dosen perawat } \\
\text { mampu mengintegrasikan pengetahuan } \\
\text { teoritis dan praktik keperawatan sehari- } \\
\text { hari }\end{array}$ & & & & & 0.860 \\
\hline
\end{tabular}




\begin{tabular}{|c|c|c|c|c|c|}
\hline Item Pernyataan & $\begin{array}{l}\text { Lngkungan } \\
\text { Pembelajaran } \\
\text { (Faktor 1) }\end{array}$ & $\begin{array}{l}\text { Gaya } \\
\text { Kepemimpinan } \\
\text { (Faktor 2) }\end{array}$ & $\begin{array}{l}\text { Perawatan } \\
\quad \text { di } \\
\text { Ruangan } \\
\text { (Faktor 3) }\end{array}$ & $\begin{array}{l}\text { Hubungan } \\
\text { Supervisi } \\
\text { (Faktor 4) }\end{array}$ & $\begin{array}{c}\text { Peran } \\
\text { Dosen } \\
\text { Perawat } \\
\text { (Faktor } \\
5 \text { ) }\end{array}$ \\
\hline $\begin{array}{l}\text { Dosen mampu mengoperasionalkan } \\
\text { tujuan pembelajaran dari penempatan }\end{array}$ & & & & & 0.780 \\
\hline klinik ini & & & & & \\
\hline $\begin{array}{l}\text { Dosen perawat membantu saya } \\
\text { mengurangi kesenjangan teori praktik }\end{array}$ & & & & & 0.722 \\
\hline $\begin{array}{l}\text { Dosen perawat seperti anggota tim } \\
\text { keperawatan }\end{array}$ & & & & & 0.750 \\
\hline $\begin{array}{l}\text { Dosen perawat mampu memberikan } \\
\text { keahlian strategi pembelajarannya } \\
\text { (pedagogisnya) kepada tim klinik }\end{array}$ & & & & & 0.757 \\
\hline $\begin{array}{l}\text { Dosen perawat dan tim klinik bekerja } \\
\text { sama dalam mendukung pembelajaran }\end{array}$ & & & & & 0.740 \\
\hline $\begin{array}{l}\text { saya } \\
\text { Pertemuan bersama antara saya, mentor }\end{array}$ & & & & & \\
\hline $\begin{array}{l}\text { dan dosen perawat adalah pengalaman } \\
\text { yang menyenangkan }\end{array}$ & & & & & 0.714 \\
\hline $\begin{array}{l}\text { Dalam pertemuan bersama kami, saya } \\
\text { merasa kami adalah rekan }\end{array}$ & & & & & 0.903 \\
\hline $\begin{array}{l}\text { Fokus pada pertemuan adalah } \\
\text { kebutuhan pembelajaran saya }\end{array}$ & & & & & 0.618 \\
\hline \multicolumn{6}{|l|}{$\begin{array}{l}\text { Eigenvalue, cummulative } \\
\text { eigenvaluedan total variance }(\%)\end{array}$} \\
\hline Eigenvalue & 3.344 & 0.694 & 0.465 & 0.300 & 0.197 \\
\hline Total Precentage & $67 \%$ & $14 \%$ & $9 \%$ & $6 \%$ & $4 \%$ \\
\hline Total explanation precentage & & & & & $67 \%$ \\
\hline
\end{tabular}

\section{b. Pembahasan}

Hasil analisis instrumen, korelasi inter-item termasuk kategori moderat hingga tinggi. Hasil analisa ini menyerupai versi bahasa Inggris dari instrumen CLES+T. Namun, pada item 1 dan 3, hasil korelasi inter-item masih kategori rendah. Hal ini dikarenakan ambiguitas penulisan "staf" yang dimaksud dalam instrumen. Oleh karena itu, beberapa ahli menyarankan untuk menambahkan "keperawatan/perawat" mengikuti kata "staf".

Untuk nilai reliabilitas cronbach alpha masuk dalam kategori moderat dibandingkan dengan instrumen versi bahasa Inggris. Hal ini dikarenakan keterbatasan jumlah responden dalam pengukuran reliabilitas penelitian ini.
Perkembangan pendidikan keperawatan di Indonesia telah berkembang sangat pesat. Berbagai tuntutan tenaga kesehatan khususnya erawa dewasa ini telah berimbas pada penyelenggaraan pendidikaan perawat. Peyelenggara pendidikan perawat semakin dituntut untuk meluluskan perawat yang berkualitas. Selain itu perkembangan perdagangan bebas, juga semakin menuntut perawat untuk mempunyai kemampuan yang lebih.

Pendidikan keperawatan yang tidak terlepas dari praktik klinik tentu memberikan andil yang besar terhadap kualitas lulusan perawat. Tidak hanya itu, susanya pembelajaran diingkungan praktik klinik juga menjadi hal yang penting dalam peningkatan keahlian dan kemampuan lulusan perawat. Sehingga diperlukan sebuah evaluasi 
yang mencakup suasana lingkungan pembelajran di klinik.

Klinik merupakan lahan pembelajaran yang sangat fluktuatif dan penuh dengan stressor. Lingkungan pembelajaran yang baik dipercayai dapat meningkatkan kemampuan belajar mahasiswa. Sehingga mahasiswa dapat menyerap ilmu praktik klinik dengan maksimal. Instrumen ini dapat digunakan untuk mengevaluasi suasana lingkungan pembelajaran klinik.

\section{KESIMPULAN}

Penelitian ini hanya menggunakan 46 responden dan diambil dari satu instusi. Mengingat keberagaman budaya Indonesia, disarankan untuk dapat dilakukan uji dari berbagai insitusi penyelenggara pendidikan perawat.

Instrumen ini telah terbuki secara valid dan reliabel dalam versi bahasa Indonesia. Dengan instrumen ini diharapkan menjadi dasar untuk evaluasi praktik pembelajaran klinik keperawatan di Indonesia.

\section{Acknowledgement}

Penggunaan instrumen ini telah memperoleh ijin dan dukungan sepenuhnya dari Miikko Saarikoski.

\section{DAFTAR PUSTAKA}

CHAN, D. S. K. 2003. Validation of the Clinical Learning Environment Inventory. Western Journal of Nursing Research, 25, 519-532.

GUILLEMIN, F., BOMBARDIER, C. \& BEATON, D. 1993. Croosscultural adaptation of health related quality of life measures: Literature review and proposed guidelines. Journal of Clinical Epidemiology, 46, 1417-1432.

IP, W. Y. \& KIT CHAN, D. S. 2005. Hong Kong nursing students' perception of the clinical environment: a questionnaire survey. Int J Nurs Stud, 42, 665-672.

PAPASTAVROU, E., LAMBRINOU, E., TSANGARI, H., SAARIKOSKI, M. \& LEINOKILPI, H. 2010. Student nurses experience of learning in the clinical environment. Nurse Education in Practice, 10, 17682.

PAPP, I., MARKKANEN, M. \& VON BONSDORFF, M. 2003. Clinical environment as a learning environment: student nurses' perceptions concerning clinical learning experiences. Nurse Education Today, 23, 262-268.

POLIT, D. F. \& BECK, C. T. 2006. The content validity index: Are you sure you know what's being repeorted? Critique and recomendations. Research in Nursing \& Health, 29, 489497.

SAARIKOSKI, M. 2002. Clinical Learning environment and supervision: Development and validation of the CLES evaluation sclae. Doctorate, Turku University.

SAARIKOSKI, M., ISOAHO, H., WARNE, T. \& LEINO-KILPI, H. 2008. The nurse teacher in clinical practice: Developing 
the new sub-dimension to the clinical learning environment and supervision (CLES) scale. International Journal of Nursing Studies, 45, 12331237.

SAARIKOSKI, M., LEINO-KILPI, H. \& WARNE, T. 2002. Clinical learning environment and supervision: Testing a research instrument in an international comparetive study. Nurse Education Today, 22, 340-349.
WARNE, T., JOHANSSON, U. B., PAPASTAVROU, E., TICHELAAR, E., TOMIETTO, M., VAN DEN BOSSCHE, K., MORENO, M. F. \& SAARIKOSKI, M. 2010. An exploration of the clinical learning experience of nursing students in nine European countries. Nurse Educaton Today, 30, 809-15. 